Article

\title{
Density Functional Theory Applied to Excited State Intramolecular Proton Transfer in Imidazole-, Oxazole-, and Thiazole-Based Systems
}

\author{
Fabricio de Carvalho, Maurício D. Coutinho Neto, Fernando H. Bartoloni * (10) and \\ Paula Homem-de-Mello * (D) \\ Centro de Ciências Naturais e Humanas, Universidade Federal do ABC, Santo André, São Paulo 5001, Brazil; \\ fabricio.carvalho@ufabc.edu.br (F.d.C.); mauricio.neto@ufabc.edu.br (M.D.C.N.) \\ * Correspondence: fernando.bartoloni@ufabc.edu.br (F.H.B.); paula.mello@ufabc.edu.br (P.H.-d.-M.); \\ Tel.: +55-11-4996-8358 (F.H.B.); +55-11-4996-0166 (P.H.-d.-M.)
}

Received: 16 April 2018; Accepted: 17 May 2018; Published: 21 May 2018

\begin{abstract}
Excited state intramolecular proton transfer (ESIPT) is a photoinduced process strongly associated to hydrogen bonding within a molecular framework. In this manuscript, we computed potential energy data using Time Dependent Density Functional Theory (TDDFT) for triphenylsubstituted heterocycles, which evidenced an energetically favorable proton transfer on the excited state (i.e., ESIPT) but not on the ground state. Moreover, we describe how changes on heterocyclic functionalities, based on imidazole, oxazole, and thiazole systems, affect the ESIPT process that converts an enolic species to a ketonic one through photon-induced proton transfer. Structural and photophysical data were obtained theoretically by means of density functional theory (DFT) calculations and contrasted for the three heterocyclics. Different functionals were used, but B3LYP was the one that adequately predicted absorption data. It was observed that the intramolecular hydrogen bond is strengthened in the excited state, supporting the occurrence of ESIPT. Finally, it was observed that, with the formation of the excited state, there is a decrease in electronic density at the oxygen atom that acts as proton donor, while there is a substantial increase in the corresponding density at the nitrogen atom that serves as proton acceptor, thus, indicating that proton transfer is indeed favored after photon absorption.
\end{abstract}

Keywords: ESIPT; DFT; hydrogen bonding; imidazole; oxazole; thiazole

\section{Introduction}

The dynamics of excited state intramolecular proton transfer (ESIPT) has been investigated both experimentally and theoretically by different research groups [1-16], since the first observation of this phenomenon by Weller et al. in 1956 [17,18]. A large number of applications are based on ESIPT, such as laser dyes [19-24], solar energy concentrators [25], chemosensors [26,27], electroluminescent materials [28], photostabilizers [29,30], molecular probes [31], and metallic ion sensors [32-35].

ESIPT is a photoinduced process observed in organic compounds containing at least one potential proton donor group (e.g., $-\mathrm{OH},-\mathrm{NH}_{2}$, and $\mathrm{NHSO}_{2} \mathrm{R}$ ) and an equivalent proton acceptor group $(-\mathrm{N},-\mathrm{C}=\mathrm{O}$, etc.), separated by no more than $2.0 \AA$ [36]. The presence of the intramolecular hydrogen bond can directly influence the geometry of the molecules [37-43]. Moreover, intramolecular hydrogen bonding in the excited state would affect non-adiabatic processes that occur after photon absorption, such as internal conversion, intersystem crossing, intramolecular charge transfer, and so on [43,44].

ESIPT is more efficient as the acidity and/or basicity of donor and acceptor groups increase after photoexcitation [45-47]. Basically, molecules that undergo ESIPT have the thermodynamically favored 
enolic form in the ground state $\left(\mathrm{S}_{0}\right.$, Scheme 1$)$ [48], which is stabilized by the intramolecular hydrogen bond. After photoexcitation, the donor group acidity and the basicity of the acceptor core must increase simultaneously due to redistribution of charge density on the chromophore. This process allows the migration of the proton from the acid to the basic center, generating the phototautomer [49].

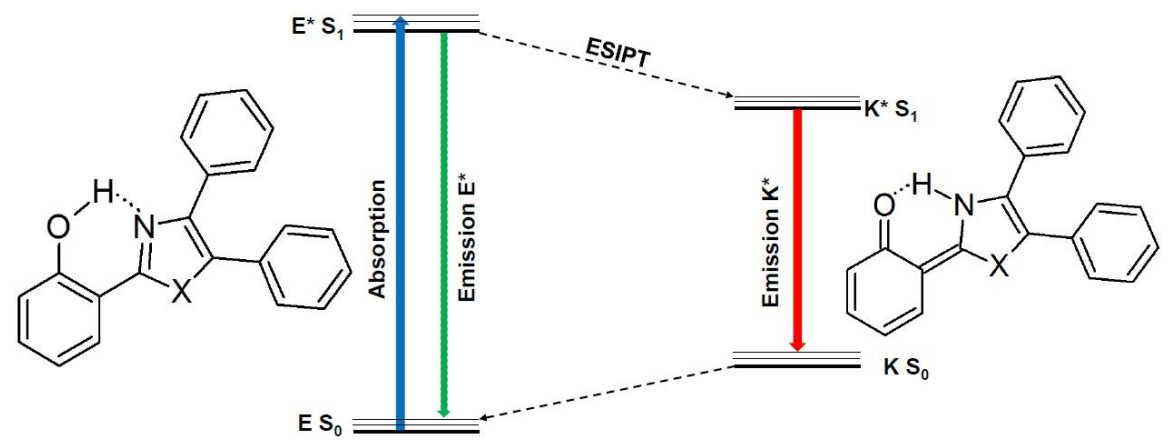

Scheme 1. Excited state intramolecular proton transfer (ESIPT) mechanism within a triphenilimidazolyc framework. Adapted from reference [34].

ESIPT is a very fast process occurring on a time scale of picoseconds [2] and even femtoseconds [50], depending on the experimental conditions. Particularly, the employed solvent [50,51] and certain substituents introduced in the molecule [50] can shift the ESIPT time scale, since the transition state barrier is affected by all these factors. Generally, ESIPT chromophores show dual emission, a normal emission from the enolic form, at lower wavelengths, and a second emission with large Stokes shift (above 8,000 $\mathrm{cm}^{-1}$ ) due to the tautomer formed after proton transfer [35] (Scheme 1). The excited enolic form $\left(\mathrm{E}^{*}\right)$ can undergo a radiative decay and return to the enolic fundamental state $(\mathrm{E})$, or it may undergo ESIPT to generate the excited ketone species $\left(\mathrm{K}^{*}\right)$, which decays emitting at lower energy than the $\mathrm{E}^{*}$ form; the large Stokes shift is due to substantial geometry reorganization [52].

Purkayastha et al. studied the rotamerization and the ESIPT process for 2-(2'-hydroxyphenyl) benzoxazole (HBO), 2-(2'-hydroxyphenyl)benzimidazole (HBI), and 2-(2'-hydroxyphenyl)benzothiazole (HBT, Figure 1) [5]. Three signals in the fluorescence spectra were observed for HBO and HBI, whereas HBT presented only two emission signals. The authors attributed this phenomenon to the existence of two rotamers for $\mathrm{HBO}$ and HBI, while there is only one for HBT. Intramolecular proton transfer for these three compounds is unfavorable in the ground state, both thermodynamically and kinetically, and these factors contribute to the occurrence of ESIPT in the lowest singlet and triplet states [5].

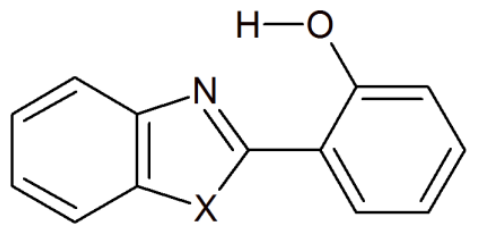

Figure 1. Enolic form for 2-(2'-hydroxyphenyl)benzoxazole (HBO) $(\mathrm{X}=\mathrm{O}), 2$-(2'-hydroxyphenyl) benzimidazole $(\mathrm{HBI})(\mathrm{X}=\mathrm{NH})$, and 2-(2'-hydroxyphenyl)benzothiazole $(\mathrm{HBT})(\mathrm{X}=\mathrm{S})[5]$.

Considering the various applications and importance of the ESIPT process for a wide class of molecules, this manuscript presents a theoretical study of the heterocyclic functionality effect in triphenylimidazole, triphenyloxazole, and triphenylthiazole systems (Figure 2). While experimental data only provides indirect information on the ESIPT mechanism and is often limited by the availability of synthesized compounds, computational methods are relevant tools to obtain structural and electronic properties, and also to give insight on these reactions mechanism. So, this work may shed light on the role of different heteroatoms on ESIPT processes. 


\section{Results and Discussion}

The proton transfer mechanism and the role of the heteroatom for three proposed triphenylsubstituted compounds, 2-(4,5-diphenyl-1H-imidazol-2-yl)phenol $\left(\mathrm{N}_{\mathrm{E}}\right)$, 2-(4,5-diphenyl-1,3-oxazol2-yl)phenol $\left(\mathrm{O}_{\mathrm{E}}\right)$, and 2-(4,5-diphenyl-1,3-thiazol-2-yl)phenol $\left(\mathrm{S}_{\mathrm{E}}\right)$, was investigated. Subscripts $\mathrm{E}$ and $\mathrm{K}$ are related to the enolic and ketonic species in the ground state; when these are accompanied by an * mark, they refer to the corresponding species in the excited state (i.e., $\mathrm{E}^{*}$ and $\mathrm{K}^{*}$ ). Therefore, $\mathrm{N}_{\mathrm{E}^{*}}$ refers to the enolic excited state of the triphenylimidazole system, while $\mathrm{O}_{\mathrm{K}}$ to the ketonic ground state of the triphenyloxazole one, and so on.

Table S1 presents and compares the calculated data for the $S_{E}$ species, with the data for HBT (Figure 1) from Purkayastha et al. [5] together with its corresponding crystallographic data [53]. It can be seen that the bond distances and angles of the heterocyclic functionality are very similar, although there are differences on the molecular framework on a larger scale for these triphenylthiazole and benzothiazole systems.

Table 1 shows the obtained values of free energy differences for the studied $\mathrm{N}_{\mathrm{E}}, \mathrm{O}_{\mathrm{E}}$, and $\mathrm{S}_{\mathrm{E}}$ triphenyl-substituted derivatives. The closed form (Figure 2) of the enolic species was considered as the reference for all cases (Table 1), and it can be verified that the open structure for the three heterocyclic systems is always less stable. Also for all derivatives, the rotamer is more stable than the open form, but less stable than the closed enolic species, indicating that intramolecular hydrogen bonding stabilizes the molecular framework, as expected, because a six-membered system is formed [54]. It is worth noting that $\mathrm{O}_{\mathrm{E}}$ rotamer is more stable than the other rotamers due the $\mathrm{O}-\mathrm{H} \cdots \mathrm{O}$ hydrogen bonding established, but still less stable than the closed form. $\mathrm{N}_{\mathrm{E}}$ and $\mathrm{S}_{\mathrm{E}}$ are less stable since no effective hydrogen bonding is expected (in $\mathrm{N}_{\mathrm{E}}$, the nitrogen atom in position 5 , Figure 2, is also connected to hydrogen). As mentioned before, the compounds studied by Purkayastha et al. [5] may present both $\mathrm{O}_{\mathrm{E}}$ and $\mathrm{N}_{\mathrm{E}}$ rotamers, with energy differences smaller than $0.6 \mathrm{kcal} \mathrm{mol}^{-1}$ associated to the closed forms, while for the compounds studied here the relative energies are about ten times greater. So, further computational and experimental studies should be performed to confirm the existence of rotamers for the triphenylic compounds.

Table 1. Relative free energy, in $\mathrm{kcal} \mathrm{mol}^{-1}$, for the $\mathrm{N}_{\mathrm{E}}, \mathrm{O}_{\mathrm{E}}$, and $\mathrm{S}_{\mathrm{E}}$ in the ground state, in the closed, open, and rotamer forms.

\begin{tabular}{|c|c|c|c|}
\hline & Closed Form $\left(\mathrm{kcal} \mathrm{mol}^{-1}\right)$ & Open Form (kcal mol $\left.{ }^{-1}\right)$ & Rotamer (kcal mol-1) \\
\hline $\mathbf{N}_{\mathrm{E}}$ & 0 & 13.55 & 8.47 \\
\hline $\mathrm{O}_{\mathrm{E}}$ & 0 & 12.55 & 5.77 \\
\hline $\mathrm{S}_{\mathrm{E}}$ & 0 & 12.68 & 9.48 \\
\hline
\end{tabular}
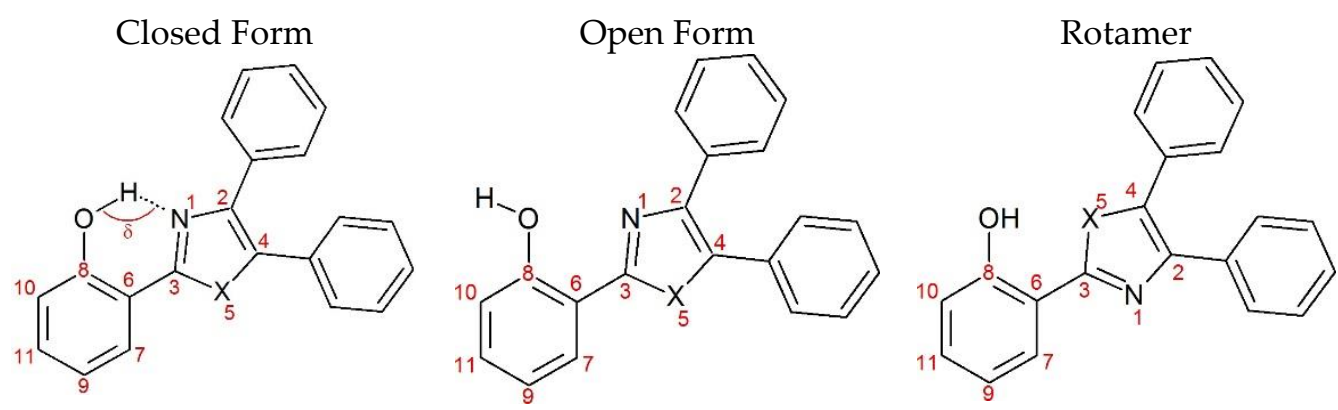

Figure 2. General structure for triphenylimidazole $\left(\mathrm{N}_{\mathrm{E}}\right.$, with $\left.\mathrm{X}=\mathrm{NH}\right)$, triphenyloxazole $\left(\mathrm{O}_{\mathrm{E}}\right.$, with $\mathrm{X}=\mathrm{O})$ and triphenylthiazole $\left(\mathrm{S}_{\mathrm{E}}\right.$, with $\left.\mathrm{X}=\mathrm{S}\right)$, and respective conformers.

The analysis of how the proton transfer coordinate advances is a crucial point for the construction of the potential energy curves in the ground and excited states. Initially, the geometries of the molecules 
in the enolic species, both in the ground state and in the excited state, were minimized without any geometric restriction. To obtain the ketone tautomer $(\mathrm{K})$, it was necessary to constrain the $\mathrm{N}-\mathrm{H}$ bond distance during geometry optimization. So, potential energy curves for the conversion from enolic to ketonic species, both in fundamental $\left(S_{0}\right)$ and in the first excited state $\left(S_{1}\right)$, were constructed based on a relaxed scan for the variation of the $\mathrm{O}-\mathrm{H}$ bond, with a $0.06 \AA$ step, and, for each step, vertical transitions were calculated with TD-DFT using the same basis set and functional as for the ground state calculation. For each step, we have evaluated the influence of the $\mathrm{O}-\mathrm{H}$ bond distance over the $\mathrm{O}-\mathrm{H} \cdots \mathrm{N}$ angle and the distance between the oxygen and nitrogen atoms $\left(\mathrm{O}-\mathrm{N}\right.$ distance), for compounds $\mathrm{N}_{\mathrm{E}}$, $\mathrm{O}_{\mathrm{E}}$, and $\mathrm{S}_{\mathrm{E}}$ (Figure 3). At low $\mathrm{O}-\mathrm{H}$ bond lengths the decrease in the distance between the oxygen and nitrogen atoms occurs gradually and then reaches a minimum at $1.24 \AA$ for $\mathrm{N}_{\mathrm{E}}, 1.26 \AA$ for $\mathrm{O}_{\mathrm{E}}$, and 1.25 $\AA$ for $S_{E}$, where the proton is transferred. After proton transfer, the distance between the phenolic oxygen atom and the nitrogen of the heterocyclic functionality increases again. The opposite occurs for the variation of the $\mathrm{O}-\mathrm{H} \cdots \mathrm{N}$ with $\mathrm{O}-\mathrm{H}$ bond length: before proton transfer the angle increases, while a decrease is observed for larger $\mathrm{O}-\mathrm{H}$ distances (Figure 3).
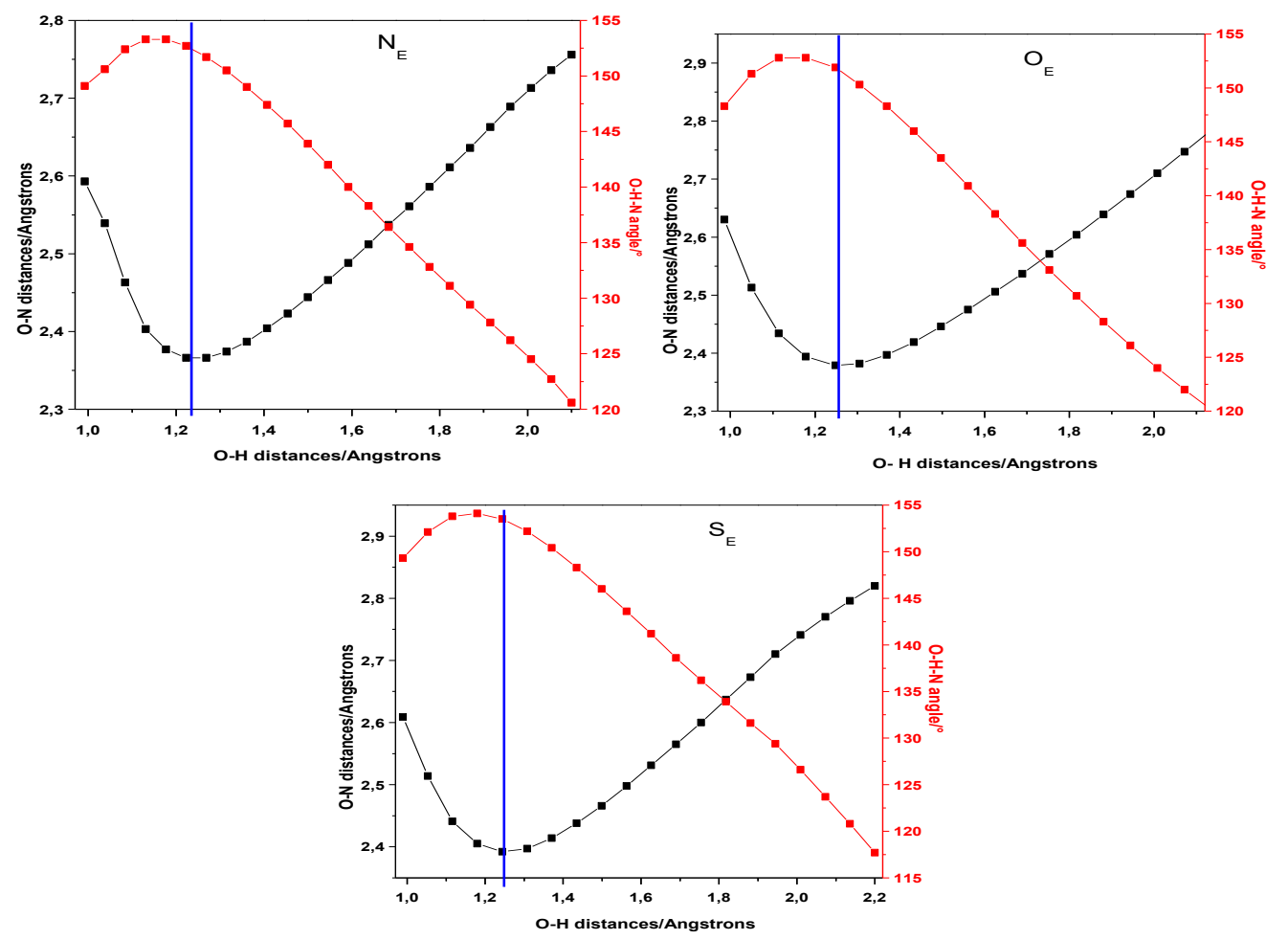

Figure 3. Variation of $\mathrm{O}-\mathrm{N}$ distance (in black, left $\mathrm{y}$-axis) and $\mathrm{O}-\mathrm{H} \cdots \mathrm{N}$ angle (in red, right $\mathrm{y}$-axis) for $\mathrm{N}_{\mathrm{E}}, \mathrm{O}_{\mathrm{E}}$, and $\mathrm{S}_{\mathrm{E}}$ with changes on the $\mathrm{O}-\mathrm{H}$ distance. The blue line indicates in which $\mathrm{O}-\mathrm{H}$ distance the proton is transferred.

The potential energy curves obtained here for the three systems (Figure 4) indicate that in the ground state proton transfer is not allowed: at the distance of ca. $1.2 \AA$ (the distance of proton transfer), the energy difference regarding the enolic minima increases to about $16\left(\mathrm{~N}_{\mathrm{E}}\right), 22\left(\mathrm{O}_{\mathrm{E}}\right)$, and $17\left(\mathrm{~S}_{\mathrm{E}}\right) \mathrm{kcal} \mathrm{mol}^{-1}$. However, in the excited state, there is an energy barrier for proton transfer of $0.97,0.02$, and $0.29 \mathrm{kcal} \mathrm{mol}^{-1}$ for $\mathrm{N}_{\mathrm{E}^{*}}, \mathrm{O}_{\mathrm{E}^{*}}$, and $\mathrm{S}_{\mathrm{E}^{*}}$, respectively. These processes could even be considered barrierless, if the average errors associated to the method employed are taken into account, meaning that the ESIPT process goes smoothly for all cases. Moreover, substitution of a nitrogen atom by oxygen or sulfur makes the proton transfer even more favored, as seen by the aforementioned energy barriers at the excited state. 

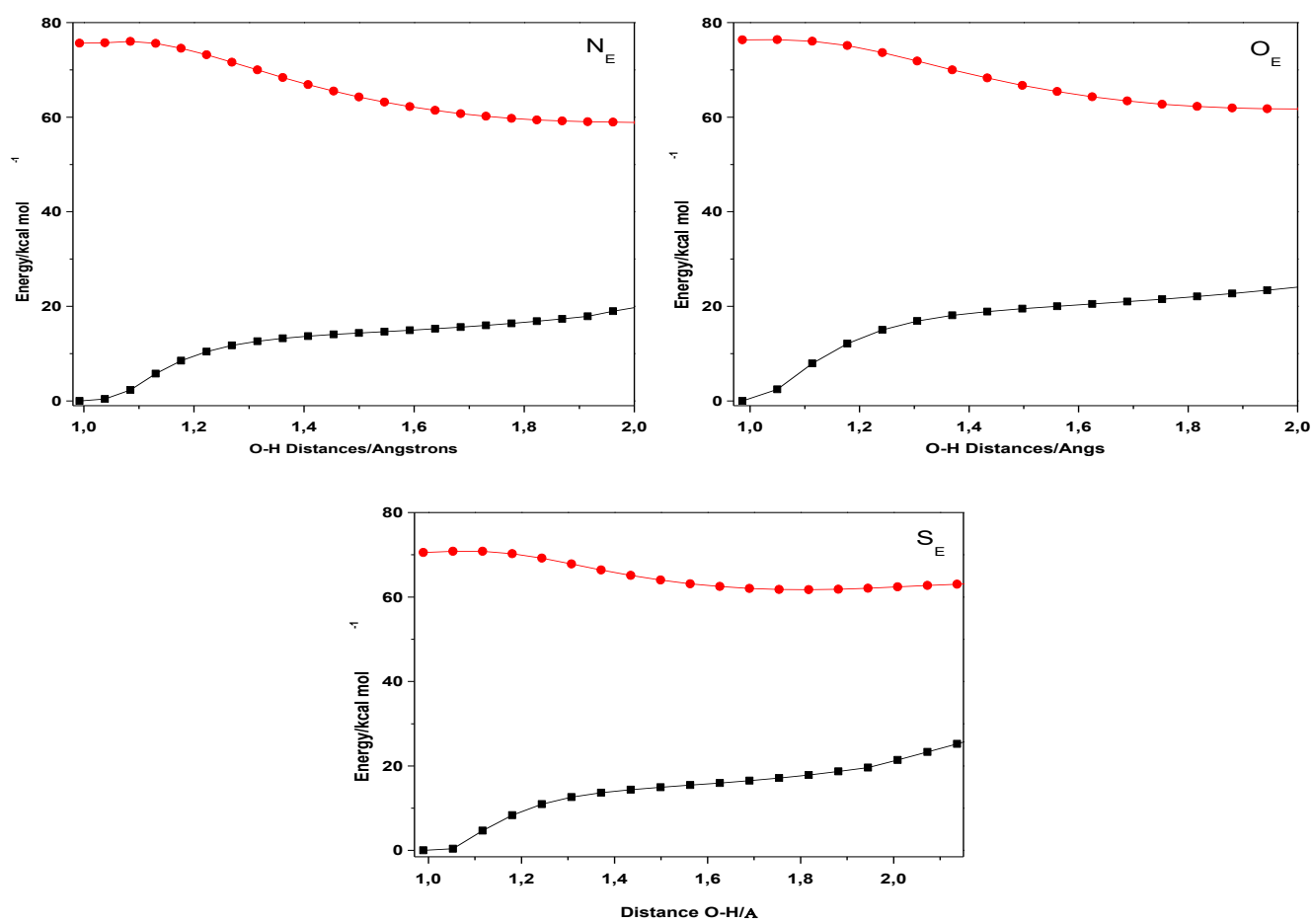

Figure 4. Calculated potential energy curves for the $S_{0}$ (in black) and $S_{1}$ (in red) states of $N_{E}, O_{E}$, and $\mathrm{S}_{\mathrm{E}}$, respectively, along the proton transfer coordinate.

Table 2 contains the main structural parameters for the compounds as the enolic species, both in the fundamental (E) and excited $\left(E^{*}\right)$ states (optimized structures for enolic species are in the Supporting Information, Figure S1). For the three systems, $\mathrm{O}-\mathrm{H}$ bond length increases in the excited state, when compared to the ground state, about $0.017,0.019$, and $0.014 \AA$, for $\mathrm{N}_{\mathrm{E}}, \mathrm{O}_{\mathrm{E}}$, and $\mathrm{S}_{\mathrm{E}}$, respectively. This increment in bond distance in the excited state indicates that there is a strengthening of intramolecular hydrogen bonding between the $\mathrm{H}$ and $\mathrm{N}$ atoms. As mentioned in the Introduction, donor $(\mathrm{O}-\mathrm{H})$ and acceptor $(\mathrm{N})$ groups are separated by distances smaller than $2.0 \AA$, about $1.7 \AA$ in the ground state. The strengthening of the hydrogen bond can be expressed also by the decrease of $\mathrm{N} \cdots \mathrm{H}$ distance: about $0.058,0.073$, and $0.064 \AA$, for $\mathrm{N}_{\mathrm{E}}, \mathrm{O}_{\mathrm{E}}$, and $\mathrm{S}_{\mathrm{E}}$, respectively, which facilitates proton transfer [44,55-57]. This phenomenon is especially relevant for the $\mathrm{O}_{\mathrm{E}}$ compound, for which there is the greatest variation in the distance and, consequently, the smallest barrier for proton transfer in the excited state. The $\delta_{\mathrm{O}-\mathrm{H} \cdots \mathrm{N}}$ angle increases $0.9^{\circ}$ for $\mathrm{N}_{\mathrm{E}}, 1.9^{\circ}$ for $\mathrm{O}_{\mathrm{E}}$, and $1.8^{\circ}$ for $\mathrm{S}_{\mathrm{E}}$, emphasizing that hydrogen bonding is stronger in the excited state, mainly for $\mathrm{O}_{\mathrm{E}}$ and $\mathrm{S}_{\mathrm{E}}$.

Analyzing the $\mathrm{C}_{8}-\mathrm{O}$ bond distance (Table 2), for the three studied systems, there was a decrease in this bond length in the excited state, in comparison to the ground state, of $0.017,0.018$, and $0.012 \AA$, for $\mathrm{N}_{\mathrm{E}}, \mathrm{O}_{\mathrm{E}}$, and $\mathrm{S}_{\mathrm{E}}$, respectively. This indicates an increment of double bond character in the excited state, which is a characteristic of compounds that undergo ESIPT [58-60]. The highest carbon-heteroatom bond distances were observed for the triphenylthiazole system, particularly, for $\mathrm{C}_{3}-\mathrm{S}_{5}$ and $\mathrm{C}_{4}-\mathrm{S}_{5}$ (Figure 2), in both ground and excited states. This increase in bond length was expected because the atomic radius of sulfur is higher than that of the other heteroatoms (i.e., $\mathrm{N}$ and $\mathrm{O}$ ) and its electronegativity is smaller, leading to this increase in bond distance. Also, for this thiol derivative, a more expressive increment of the bond distances in the excited state, in comparison to the ground state, is overall observed (about $0.02 \AA$, Table 2 and Table S2). Contrarily, for the imidazolic system, there is no systematic increase or decrease in bond lengths when the excited state is generated from the fundamental one. 
Table 2. Bond length $(\AA)$ and angle formed by $\mathrm{O}-\mathrm{H} \cdots \mathrm{N}\left(\delta_{\mathrm{O}-\mathrm{H} \cdots \mathrm{N}}{ }^{\circ}\right)$ for enolic form of $\mathrm{N}_{\mathrm{E}}, \mathrm{S}_{\mathrm{E}}$, and $\mathrm{O}_{\mathrm{E}}$ in ground state $\left(S_{0}=E\right)$ and first excited singlet state $\left(S_{1}={ }_{E}^{*}\right)$.

\begin{tabular}{ccccccc}
\hline & $\mathbf{N}_{\mathbf{E}}$ & $\mathbf{N}_{\mathbf{E}^{*}}$ & $\mathbf{O}_{\mathbf{E}}$ & $\mathbf{O}_{\mathbf{E}^{*}}$ & $\mathbf{S}_{\mathbf{E}}$ & $\mathbf{S}_{\mathbf{E}^{*}}$ \\
\hline $\mathbf{O}-\mathbf{H}$ & 0.992 & 1.009 & 0.986 & 1.005 & 0.989 & 1.003 \\
$\mathbf{H} \cdots \mathbf{N}$ & 1.711 & 1.653 & 1.765 & 1.692 & 1.742 & 1.678 \\
$\mathbf{X}_{5}-\mathbf{C}_{3}$ & 1.364 & 1.382 & 1.351 & 1.360 & 1.751 & 1.776 \\
$\mathbf{X}_{5}-\mathbf{C}_{4}$ & 1.388 & 1.379 & 1.385 & 1.393 & 1.747 & 1.767 \\
$\boldsymbol{\delta}_{\mathbf{O}-\mathbf{H} \cdots \mathbf{N}}$ & 148.8 & 149.7 & 147.0 & 148.9 & 147.9 & 149.7 \\
\hline
\end{tabular}

Atom numbering from Figure 2.

From the theoretically obtained IR vibrational spectra (Figures S2-S4), the vibrational stretching frequency of the $\mathrm{O}-\mathrm{H}$ bond in the ground state appears in the following sequence: $3225 \mathrm{~cm}^{-1}$ for $\mathrm{N}_{\mathrm{E}}$, $3350 \mathrm{~cm}^{-1}$ for $\mathrm{O}_{\mathrm{E}}$, and $3290 \mathrm{~cm}^{-1}$ for $\mathrm{S}_{\mathrm{E}}$, in agreement with $\mathrm{O}-\mathrm{H}$ bond length and $\delta_{\mathrm{O}-\mathrm{H} \cdots \mathrm{N}}$ angle increment order. In the excited state, this order in energy is maintained between functionalities, but the vibrational transitions appear at lower wavenumbers, with a decrease of $265 \mathrm{~cm}^{-1}$ for $\mathrm{N}_{\mathrm{E}}, 235 \mathrm{~cm}^{-1}$ for $\mathrm{S}_{\mathrm{E}}$, and only $85 \mathrm{~cm}^{-1}$ for $\mathrm{O}_{\mathrm{E}}$. So, for the three studied systems, there was a shift towards the bathochromic region (i.e., lower energy) of the $\mathrm{O}-\mathrm{H}$ group stretching signal, thus indicating that the intramolecular hydrogen bonding in $\mathrm{O}-\mathrm{H} \cdots \mathrm{N}$ is strengthened, mainly for $\mathrm{N}_{\mathrm{E}}$ and $\mathrm{S}_{\mathrm{E}}$.

Table 3 presents the experimentally determined $\mathrm{p} K_{\mathrm{aH}}$ values from the literature for $1 H$-imidazole [61], 1,3-oxazole and 1,3-thiazole [62], thus, for the heterocyclic functionality without phenyl substituents; while protonated oxazole is the more acidic species, the imidazolic heterocycle is more basic. We have, then, obtained the difference in free energies for protonated and deprotonated forms of these molecules (i.e., $\Delta \Delta \mathrm{G}$ ) by frequency calculations. Even though to obtain the $\mathrm{p} K_{\mathrm{aH}}$ theoretically further studies would be necessary, from the present data it can be already seen (Table 3), that the trend in $\Delta \Delta G$ values correspond to the one in $\mathrm{p} K_{\mathrm{aH}}$, with a more negative free energy associated to an increased basicity.

Table 3. Theoretically obtained free energy differences between protonated and deprotonated forms of heterocyclic compounds and their respective experimental $\mathrm{p} K_{\mathrm{aH}}$ values.

\begin{tabular}{cccc}
\hline & $\mathbf{1 H}$-Imidazole & $\mathbf{1 , 3 - O x a z o l e}$ & $\mathbf{1 , 3 - T h i a z o l e}$ \\
\hline $\boldsymbol{\Delta} \boldsymbol{\Delta G}\left(\mathrm{kcal} \mathrm{mol}^{-\mathbf{1}}\right)$ & -230.61 & -213.79 & -219.25 \\
$\mathrm{p} K_{\mathrm{aH}}$ & $6.9^{\mathrm{a}}$ & $0.8^{\mathrm{b}}$ & $2.5^{\mathrm{b}}$ \\
\hline
\end{tabular}

Taken from references ${ }^{\mathrm{a}}[61]$ and $^{\mathrm{b}}[62]$.

By the data in Table 4, containing atomic charges derived from the electrostatic potential (calculated with the ChelpG scheme), it can be verified that both the enolic and ketonic species of the studied compounds present the oxygen atom of the phenolic group with a more negative charge than the basic nitrogen atom of the heterocyclic functionality. This contributes for a higher stability of the enol tautomer at the ground state $\left(\mathrm{N}_{\mathrm{E}}, \mathrm{O}_{\mathrm{E}}\right.$, and $\left.\mathrm{S}_{\mathrm{E}}\right)$ when compared to the corresponding ketonic species.

Table 4. ChelpG charges in the ground state for the enolic and ketonic species of the imidazolic, oxazolic, and thiazolic heterocyclic systems, regarding the atoms involved in intramolecular hydrogen bonding.

\begin{tabular}{ccccccc}
\hline Atom & $\mathbf{N}_{\mathbf{E}}$ & $\mathbf{N}_{\mathbf{K}}$ & $\mathbf{S}_{\mathbf{E}}$ & $\mathbf{S}_{\mathbf{K}}$ & $\mathbf{O}_{\mathbf{E}}$ & $\mathbf{O}_{\mathbf{K}}$ \\
\hline $\mathbf{N}$ & -0.4151 & -0.2140 & -0.4254 & -0.2456 & -0.3325 & -0.1723 \\
$\mathbf{O}$ & -0.5118 & -0.6061 & -0.4961 & -0.5698 & -0.4933 & -0.5735 \\
$\mathbf{H}$ & 0.3309 & 0.3004 & 0.3280 & 0.3167 & 0.3177 & 0.2896 \\
\hline
\end{tabular}

To deepen the study of the heteroatom influence over the electronic distribution both on ground and excited states, electronic transitions regarding absorption of light were simulated (Figures S5-S7). 
Experimentally, the triphenylimidazole compounds present two absorption signals, the first at $322 \mathrm{~nm}$, attributed mainly to a HOMO $\rightarrow$ LUMO transition, and the second at $294 \mathrm{~nm}$, corresponding mainly to a $\mathrm{HOMO} \rightarrow \mathrm{LUMO}+1$ transition [34]. Jayabharathi et al. obtained experimental absorption spectra with a well-defined band for some benzimidazole derivatives, which have a phenolic hydroxyl group hydrogen bonded intramolecularly with the nitrogen atom [63]. However, Wang et al. have obtained the absorption spectrum of a compound derived from benzothiazole which has two absorption bands, therefore, it can be seen that the features of the absorption spectrum may change according to the structure of the compound [64]. On the other hand, only one signal dominates the experimental emission spectra for two $N_{E}$ derivatives (see for example references [34,35]), associated to the $\mathrm{K}^{*}$ tautomer deactivation. Emission of the $\mathrm{E}^{*}$ species occurs at shorter wavelengths, and can be experimentally observed when ESIPT is prevented due to complexation with metallic species [34,35].

Particularly for the $\mathrm{N}_{\mathrm{E}}$ triphenylimidazole derivative, an excellent agreement between experimental and calculated absorption data has been observed using the B3LYP functional [35]. B3LYP has been applied successfully $[58,65-70]$ in similar systems, when compared to available experimental data, although this functional has been shown to present limitations due to its generality (see for example reference [71]). Therefore, we have evaluated the $\mathrm{N}_{\mathrm{E}}$ absorption spectrum with different functionals (B3LYP, M06, wB97X-D3, and M06-2X, Table S2). Although there were no changes in molecular orbital contributions, B3LYP still was the best functional to adequately predict absorption data, followed by M06. For the compounds object of this study, the first transition (HOMO $\rightarrow$ LUMO character) occurs almost at the same region for $\mathrm{O}_{\mathrm{E}}$ and $\mathrm{N}_{\mathrm{E}}$, around $338 \mathrm{~nm}$, and at a less energetic region for $\mathrm{S}_{\mathrm{E}}$ (at $346 \mathrm{~nm}$ ). However, when the same analysis is carried out with respect to the transition with $\mathrm{HOMO} \rightarrow \mathrm{LUMO}+1$ character, this order is inverted: $\mathrm{N}_{\mathrm{E}}$ exhibits a maximum absorption wavelength of $311 \mathrm{~nm}$, followed by $\mathrm{O}_{\mathrm{E}}$ at $305 \mathrm{~nm}$ and $\mathrm{S}_{\mathrm{E}}$ at $303 \mathrm{~nm}$ (Table 5). Figure 5 indicates that these differences correspond to the decrease in the HOMO-LUMO energy gap in the following order $\mathrm{N}_{\mathrm{E}}>\mathrm{O}_{\mathrm{E}}>\mathrm{S}_{\mathrm{E}}$, with the decrease in the LUMO energy level contributing more to changes in the energy gap. On the other hand, LUMO +1 is less affected by changing the heteroatom, so the second transition is mainly affected by the smaller changes in the HOMO energy level.

Table 5. Theoretical absorption wavelength $\left(\lambda_{\mathrm{abs}}\right)$, Oscillator strength $(f)$, contributions $(\mathrm{CI})$, and theoretical emission wavelength $\left(\lambda_{\text {emis }}\right)$ of $\mathrm{N}_{\mathrm{E}}, \mathrm{O}_{\mathrm{E}}$, and $\mathrm{S}_{\mathrm{E}}$, respectively.

\begin{tabular}{cccccc}
\hline & Main Composition & $\lambda_{\text {abs }}(\mathbf{n m})$ & $f$ & CI (\%) & $\lambda_{\text {emis }}(\mathbf{n m})$ \\
\hline \multirow{2}{*}{$\mathbf{N}_{\mathrm{E}}$} & $\mathrm{HOMO} \rightarrow$ LUMO & 337.5 & 0.3850 & 94.2 & \multirow{2}{*}{523} \\
& $\mathrm{HOMO} \rightarrow$ LUMO+1 & 310.6 & 0.4288 & 86.6 & \\
$\mathbf{O}_{\mathrm{E}}$ & $\mathrm{HOMO} \rightarrow$ LUMO & 339.1 & 0.6724 & 94.2 & \multirow{2}{*}{452} \\
& $\mathrm{HOMO} \rightarrow$ LUMO+1 & 304.9 & 0.2266 & 78.4 & \\
$\mathbf{S}_{\mathrm{E}}$ & $\mathrm{HOMO} \rightarrow$ LUMO & 346.5 & 0.5478 & 93.6 & \multirow{2}{*}{490} \\
& $\mathrm{HOMO} \rightarrow$ LUMO+1 & 302.8 & 0.1188 & 86.3 & \\
\hline
\end{tabular}

Aiming to shed light on formation of excited state, we have evaluated HOMO and LUMO electron densities of the enolic species for $\mathrm{N}_{\mathrm{E}}, \mathrm{S}_{\mathrm{E}}$, and $\mathrm{O}_{\mathrm{E}}$ (shown in Figure 6). It is verified that the HOMO of the three heterocyclic systems is distributed over the whole molecule. The HOMO $\rightarrow$ LUMO transition of the enolic species leads to a decrease in the electron density in the oxygen atom of the hydroxyl group. This trend must directly influence intramolecular hydrogen bonding, since, as previously seen, the interaction distance $-\mathrm{H} \cdots \mathrm{N}=$ is decreased after photoexcitation to the $\mathrm{S}_{1}$ state, implying an increase in strength of the intramolecular hydrogen bond, corroborating the analysis of the infrared signals of $\mathrm{S}_{0}$ and $\mathrm{S}_{1}$ states [72]. However, $\mathrm{S}_{\mathrm{E}}$ and $\mathrm{O}_{\mathrm{E}}$ presented higher electron density on the hydroxyl oxygen atom than the electron density presented for $\mathrm{N}_{\mathrm{E}}$, even though this density is smaller than in the respective HOMO orbitals. 


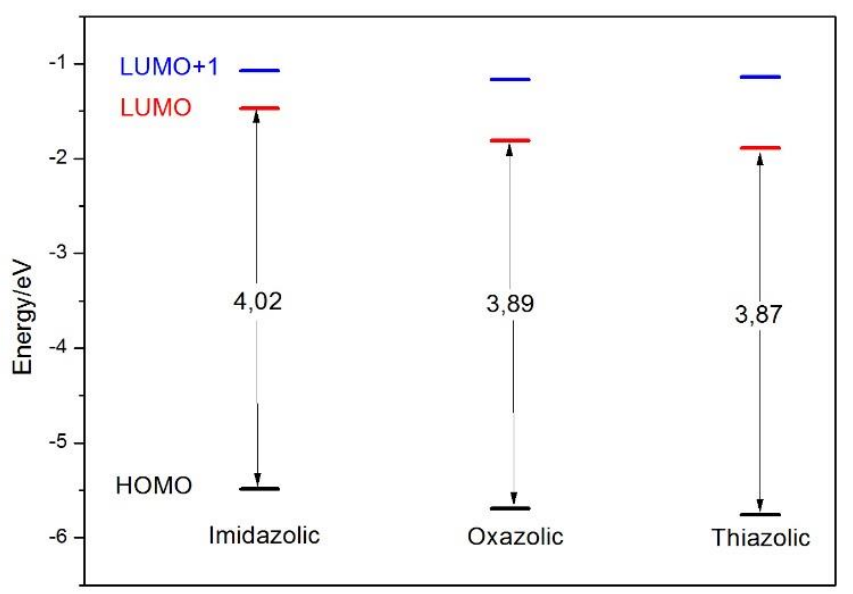

Figure 5. Representation of frontier orbital energy levels for $\mathrm{N}_{\mathrm{E}}, \mathrm{O}_{\mathrm{E}}$, and $\mathrm{S}_{\mathrm{E}}$, respectively.

It should be noted that the $S_{1}$ state change in electron density in the hydroxyl group could directly influence intramolecular hydrogen bonding (Figure 6). The interaction between the electrons of the heterocyclic system and the non-bonding orbital of the $\mathrm{OH}$ group is the one mainly responsible for the transfer of proton from the oxygen atom to the nitrogen one [72]. Consequently, the excited state of the studied systems should favor the protonation of the nitrogen atom and, consequently, the deprotonation of the phenolic group (see Supporting Information for HOMO and LUMO of ketonic forms, Figures S8-S10).

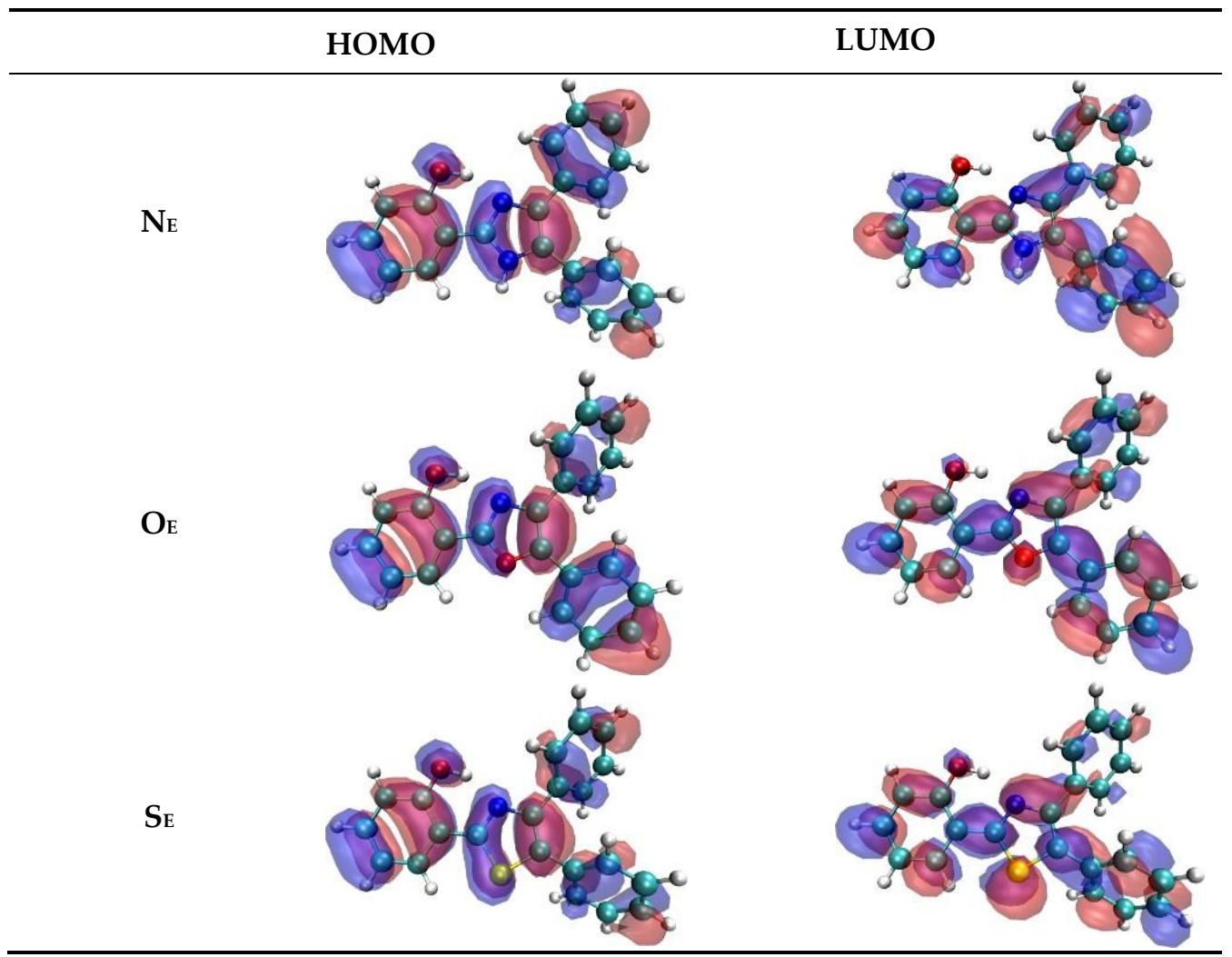

Figure 6. Molecular orbitals $\mathrm{HOMO}$ and $\mathrm{LUMO}$ for $\mathrm{N}_{\mathrm{E}}, \mathrm{O}_{\mathrm{E}}$, and $\mathrm{S}_{\mathrm{E}}$, respectively.

Once the molecule reaches a stable conformation in the excited state, already as the ketonic species, emission of energy occurs, and a new barrier-free process happens, from ketone to enolic species in 
the ground state. Wang et al. studied the fluorescence of some 2-(2'-hydroxyphenyl)benzothiazole derivatives and showed that these compounds have dual fluorescence [64]. An emission that appears at low wavelengths and is related to the fluorescence of the enolic form, and another signal that appears at higher wavelengths and is associated to the emission of the ketonic form [64,73]. When using polar solvents, just a single emission was observed for imidazolic derivatives, related to the enolic species emission, however, when using non-polar solvents, the dual emission was observed [73].

The analysis of the emission data (Table 5) indicates that the $\mathrm{N}_{\mathrm{E}}$ compound emits in a lower energy region, which shows that the gap between the excited and ground states is the most stabilized among the three studied systems, corresponding to an emission at $523 \mathrm{~nm}$. For $\mathrm{S}_{\mathrm{E}}$ and $\mathrm{O}_{\mathrm{E}}$, the emission occurs at 490 and $452 \mathrm{~nm}$, respectively, showing that the framework with the heterocyclic functionality containing the oxygen atom is the one with the highest energy difference between states.

\section{Materials and Methods}

We have employed the Density Functional Theory (DFT) and the Time-Dependent Density Functional Theory (TD-DFT) to study the ESIPT process for $\mathrm{N}_{\mathrm{E}}, \mathrm{O}_{\mathrm{E}}$ and $\mathrm{S}_{\mathrm{E}}$. These approaches have been widely used before to clarify fundamental aspects regarding the different structural and electronic states $[13,59,65,73-77]$ as well as to study theoretically the intramolecular hydrogen bonding in the excited state for different compounds for whose ESIPT occurs [44,78-83].

As mentioned above, geometries of the enolic species $\left(E\right.$ and $\left.E^{*}\right)$ were minimized without any geometric restriction, but to obtain the ketone tautomers $\left(\mathrm{K}\right.$ and $\left.\mathrm{K}^{*}\right)$, it was necessary to constrain the $\mathrm{N}-\mathrm{H}$ bond distance during geometry optimization. Vibrational frequencies of the enolic optimized structures were obtained to verify that these correspond to a minimum in the potential energy surface [84]. Besides that, frequency calculations were also used to obtain thermodynamic information for $1 \mathrm{H}$-imidazole, 1,3-oxazole and 1,3-thiazole (protonated and deprotonated species), to calculate the free energy of protonation (based on the difference of the free energies of formation) aiming to give insight on experimental $\mathrm{p} K_{\mathrm{aH}}$ values presented by the different heterocycles. TD-DFT calculations were performed to obtain the absorption spectra for both conformations using 40 states of excitation. Atomic charges were derived from electrostatic potential using ChelpG scheme. All calculations were performed with B3LYP [85-87] functional and the basis set 6-31G(2d,2p) [88] as implemented in Orca software [89], using an energy convergence criteria of $10^{-8}$ Hartree.

The potential energy curves for the proton transfer (conversion from enolic to ketonic species, both in $S_{0}$ and in $S_{1}$ ), were constructed at B3LYP/6-31G $(2 d, 2 p)$ level: for the ground state a relaxed scan for the variation of the O-H bond, with a $0.06 \AA$ step was performed and, for each step, vertical transitions were calculated with TD-DFT. This technique was used before to construct potential energy curves in the excited state and has provided good results when compared to experimental data [58,65-70]. Emission wavelength in Table 5 was calculated based on the energy difference between the minimum at the excited state of ketonic form and the same geometry at the ground state.

\section{Conclusions}

DFT and TD-DFT calculations were applied to describe the ongoing ESIPT process in triphenylimidazole, triphenyloxazole, and triphenylthiazole systems. Intramolecular proton transfer in the ground state does not occur because there is an energy barrier greater than $10 \mathrm{kcal} \mathrm{mol}^{-1}$ separating the conversion of the enolic tautomer to the ketonic one. This barrier decreases significantly $\left(<1 \mathrm{kcal} \mathrm{mol}^{-1}\right)$ after excitation to the first excited state, enabling intramolecular proton transfer. Among three different possible conformations, the one corresponding to a closed enolic form is the most stable, since intramolecular hydrogen bonding leads to an overall stabilization of the molecule. For the three systems, $\mathrm{O}-\mathrm{H}$ bond distance increases in the excited state following $\mathrm{H} \cdots \mathrm{N}$ length decrease, demonstrating that in the excited state the intramolecular hydrogen bond is strengthened; this was corroborated by simulated vibrational data. The HOMO $\rightarrow$ LUMO transition energy gap increases when the heteroatom changes from $\mathrm{S}$, to $\mathrm{O}$ and $\mathrm{N}$ in the heterocyclic system, while emission energy 
decreases for the N, S, O sequence. Electronic densities in the phenolic oxygen atom are high in the HOMO for all three systems as their enolic species, but these densities decrease after photoexcitation, marking the proton transfer. Therefore, the identity of the heterocyclic functionality is absolutely relevant on the context of intramolecular proton transfer within these frameworks. The findings reported on this study may contribute to the design of new relevant ESIPT-operating systems, particularly with respect to the identity of the heterocyclic system that acts as proton acceptor group.

Supplementary Materials: The following are available online: Tables S1 and S2; Figures S1-S10.

Author Contributions: F.d.C., F.H.B. and P.H.-d.-M. conceived and designed the experiments; F.d.C. performed the calculations; F.C., M.D.C.N. and P.H.-d.-M. analyzed the data; M.D.C.N. and F.H.B. contributed to the interpretation of the results; F.d.C. and P.H.-d.-M. took the lead in writing the manuscript; all authors provided critical feedback and helped shape the research, analysis and final manuscript.

Acknowledgments: Authors thank Brazilian agencies for financial support: F.C. thanks CAPES, P.H.M. thanks FAPESP (Proc. \# 17/23416-9) and CNPq (Proc. \# 448125/2014-5 and 448125/2014-5), and F.H.B. thanks FAPESP (Proc. \# 12/13807-7).

Conflicts of Interest: The authors declare no conflict of interest.

\section{References}

1. Eisenberger, H.; Nickel, B.; Ruth, A.A.; Alsoufi, W.; Grellmann, K.H.; Novo, M. Keto-enol tautomerization of 2-(2'-hydroxyphenyl)benzoxazole and 2-(2'-hydroxy-4'-methylphenyl)benzoxazole in the triplet-statehydrogen tunneling and isotope effects. 2. dual phosphorescence kinetics. J. Phys. Chem. 1991, 95, 10509-10518. [CrossRef]

2. Arthenengeland, T.; Bultmann, T.; Ernsting, N.P.; Rodriguez, M.A.; Thiel, W. Singlet excited-state intramolecular proton-transfer in 2-(2'-hydroxyphenyl)benzoxazole-Spectroscopy at low temperatures, femtosecond transient absorption, and MNDO calculations. Chem. Phys. 1992, 163, 43-53. [CrossRef]

3. Fernandez-Ramos, A.; Rodriguez-Otero, J.; Rios, M.A.; Soto, J. Intramolecular proton transfer in 2-(2'-hydroxyphenyl)benzoxazole: The reliability of ab initio calculations on simplified structures. J. Mol. Struct. 1999, 489, 255-262. [CrossRef]

4. Iglesias, R.S.; Goncalves, P.F.B.; Livotto, P.R. Semi-empirical study of a set of 2-(2'-hydroxyphenyl)benzazoles using the polarizable continuum model. Chem. Phys. Lett. 2000, 327, 23-28. [CrossRef]

5. Purkayastha, P.; Chattopadhyay, N. Role of rotamerisation and excited state intramolecular proton transfer in the photophysics of 2-(2'-hydroxyphenyl)benzoxazole, 2-(2'-hydroxyphenyl)benzimidazole and 2-(2'-hydroxyphenyl)benzothiazole: A theoretical study. Phys. Chem. Chem. Phys. 2000, 2, 203-210. [CrossRef]

6. Purkayastha, P.; Chattopadhyay, N. Theoretical modelling for the ground state rotamerisation and excited state intramolecular proton transfer of 2-(2'-hydroxyphenyl)oxazole, 2-(2'-hydroxyphenyl)imidazole, 2-(2'-hydroxyphenyl)thiazole and their benzo analogues. Int. J. Mol. Sci. 2003, 4, 335-361. [CrossRef]

7. Rodembusch, F.S.; Leusin, F.P.; Campo, L.F.; Stefani, V. Excited state intramolecular proton transfer in amino 2-(2'-hydroxyphenyl)benzazole derivatives: Effects of the solvent and the amino group position. J. Lumin. 2007, 126, 728-734. [CrossRef]

8. Irgibaeva, I.S.; Birimzhanova, D.A.; Barashkov, N.N. Research of electronic absorption spectra of benzazols derivatives by Ab Initio calculations. Int. J. Quantum Chem. 2008, 108, 2700-2710. [CrossRef]

9. Iijima, T.; Momotake, A.; Shinohara, Y.; Sato, T.; Nishimura, Y.; Arai, T. Excited-state intramolecular proton transfer of naphthalene-fused 2-(2'-Hydroxyaryl)benzazole Family. J. Phys. Chem. A 2010, 114, 1603-1609. [CrossRef] [PubMed]

10. Chen, W.H.; Pang, Y. Excited-state intramolecular proton transfer in 2-(2', $6^{\prime}$-dihydroxyphenyl) benzoxazole: Effect of dual hydrogen bonding on the optical properties. Tetrahedron Lett. 2010, 51, 1914-1918. [CrossRef]

11. Sepiol, J.; Grabowska, A.; Borowicz, P.; Kijak, M.; Broquier, M.; Jouvet, C.; Dedonder-Lardeux, C.; Zehnacker-Rentien, A. Excited-state intramolecular proton transfer reaction modulated by low-frequency vibrations: An effect of an electron-donating substituent on the dually fluorescent bis-benzoxazole. J. Chem. Phys. 2011, 135. [CrossRef] [PubMed] 
12. Jayabharathi, J.; Vimal, K.; Thanikachalam, V.; Kalaiarasi, V. Photophysical and excited-state intramolecular proton transfer of 2-(1-(3,5-dimethylphenyl)-1H-phenanthro [9,10-d] imidazol-2-yl)phenol: DFT analysis. Spectrochim. Acta A 2014, 125, 290-296. [CrossRef] [PubMed]

13. Houari, Y.; Chibani, S.; Jacquemin, D.; Laurent, A.D. TD-DFT Assessment of the excited state intramolecular proton transfer in hydroxyphenylbenzimidazole (HBI) dyes. J. Phys. Chem. B 2015, 119, 2180-2192. [CrossRef] [PubMed]

14. Rocha, E.P.; Ramalho, T.C. Probing the ESIPT process in 2-amino-1,4-naphthoquinone: Thermodynamics properties, solvent effect and chemometric analysis. Theor. Chem. Acc. 2016, 135, 39. [CrossRef]

15. An, B.; Yuan, H.; Zhu, Q.; Li, Y.; Guo, X.; Zhang, J. Theoretical insight into the excited-state intramolecular proton transfer mechanisms of three amino-type hydrogen-bonding molecules. Spectrochim. Acta A 2017, 175, 36-42. [CrossRef] [PubMed]

16. Manojai, N.; Daengngern, R.; Kerdpol, K.; Ngaojampa, C.; Kungwan, N. Heteroatom effect on photophysical properties of 2-(2'-hydroxyphenyl) benzimidazole and its derivatives as fluorescent dyes: A TD-DFT study. J. Lumin. 2017, 188, 275-282. [CrossRef]

17. Weller, A. Innermolekularer protonenubergang im angeregten zustand. Zeits. Elek. 1956, 60, 1144-1147.

18. Weler, A. Fast reactions of excited molecules. Prog. React. Kinet. Mech. 1961, 1, 187.

19. Chou, P.; Mcmorrow, D.; Aartsma, T.J.; Kasha, M. The proton-transfer laser-gain spectrum and amplification of spontaneous emission of 3-hydroxyflavone. J. Phys. Chem. 1984, 88, 4596-4599. [CrossRef]

20. Kasha, M. Proton-transfer spectroscopy-perturbation of the tautomerization potential. J. Chem. Soc. Trans. II 1986, 82, 2379-2392. [CrossRef]

21. Tarkka, R.M.; Zhang, X.J.; Jenekhe, S.A. Electrically generated intramolecular proton transfer: Electroluminescence and stimulated emission from polymers. J. Am. Chem. Soc. 1996, 118, 9438-9439. [CrossRef]

22. Gormin, D.; Sytnik, A.; Kasha, M. Spectroscopy of amplified spontaneous emission laser spikes in polyhydroxyflavones. J. Phys. Chem. A 1997, 101, 672-677. [CrossRef]

23. Costela, A.; Garcia-Moreno, I.; Mallavia, R.; Amat-Guerri, F.; Barroso, J.; Sastre, R. Proton-transfer lasers based on solid copolymers of modified 2-(2'-hydroxyphenyl)benzimidazoles with methacrylate monomers. Opt. Commun. 1998, 152, 89-95. [CrossRef]

24. Garcia, O.; Garrido, L.; Sastre, R.; Costela, A.; Garcia-Moreno, I. Synthetic strategies for hybrid materials to improve properties for optoelectronic applications. Adv. Funct. Mater. 2008, 18, 2017-2025. [CrossRef]

25. Vollmer, F.; Rettig, W. Fluorescence loss mechanism due to large-amplitude motions in derivatives of 2,2'-bipyridyl exhibiting excited-state intramolecular proton transfer and perspectives of luminescence solar concentrators. J. Photochem. Photobiol. A Chem. 1996, 95, 143-155. [CrossRef]

26. Shynkar, V.V.; Klymchenko, A.S.; Piemont, E.; Demchenko, A.P.; Mely, Y. Dynamics of intermolecular hydrogen bonds in the excited states of $4^{\prime}$-dialkylamino-3-hydroxyflavones. On the pathway to an ideal fluorescent hydrogen bonding sensor. J. Phys. Chem. A 2004, 108, 8151-8159. [CrossRef]

27. Chen, K.-Y.; Hsieh, C.-C.; Cheng, Y.-M.; Lai, C.-H.; Chou, P.-T. Extensive spectral tuning of the proton transfer emission from 550 to $675 \mathrm{~nm}$ via a rational derivatization of 10-hydroxybenzo[h]quinoline. Chem. Commun. 2006, 42, 4395-4397. [CrossRef] [PubMed]

28. Kwon, J.E.; Park, S.Y. Advanced organic optoelectronic materials: Harnessing excited-state intramolecular proton transfer (ESIPT) process. Adv. Mater. 2011, 23, 3615-3642. [CrossRef] [PubMed]

29. Stueber, G.J.; Kieninger, M.; Schettler, H.; Busch, W.; Goeller, B.; Franke, J.; Kramer, H.E.A.; Hoier, H.; Henkel, S. Ultraviolet stabilizers of the 2-(2'-hydroxyphenyl)-1,3,5-triazine class-structural and spectroscopic characterization. J. Phys. Chem. 1995, 99, 10097-10109. [CrossRef]

30. Keck, J.; Kramer, H.E.A.; Port, H.; Hirsch, T.; Fischer, P.; Rytz, G. Investigations on polymeric and monomeric intramolecularly hydrogen-bridged UV absorbers of the benzotriazole and triazine class. J. Phys. Chem. 1996, 100, 14468-14475. [CrossRef]

31. Wu, J.; Liu, W.; Ge, J.; Zhang, H.; Wang, P. New sensing mechanisms for design of fluorescent chemosensors emerging in recent years. Chem. Soc. Rev. 2011, 40, 3483-3495. [CrossRef] [PubMed]

32. Taki, M.; Wolford, J.L.; O'Halloran, T.V. Emission ratiometric imaging of intracellular zinc: Design of a benzoxazole fluorescent sensor and its application in two-photon microscopy. J. Am. Chem. Soc. 2004, 126, 712-713. [CrossRef] [PubMed] 
33. Rodembusch, F.S.; Brand, F.R.; Correa, D.S.; Pocos, J.C.; Martinelli, M.; Stefani, V. Transition metal complexes from 2-(2'-hydroxyphenyl)benzoxazole: A spectroscopic and thermogravimetric stability study. Mater. Chem. Phys. 2005, 92, 389-393. [CrossRef]

34. Orfão, R.B., Jr.; Alves, J.; Bartoloni, F.H. Spectroscopic studies on the interaction of metallic ions with an imidazolyl-phenolic system. J. Fluoresc. 2016, 26, 1373-1380. [CrossRef] [PubMed]

35. Orfão, R.B., Jr.; de Carvalho, F.; Homem-de-Mello, P.; Bartoloni, F.H. On the fluorescent, steric and electronic factors affecting the detection of metallic ions using an imidazolyl-phenolic derived fluorescent probe. J. Braz. Chem. Soc. 2017, 28, 1896-1904. [CrossRef]

36. Das, K.; Sarkar, N.; Ghosh, A.K.; Majumdar, D.; Nath, D.N.; Bhattacharyya, K. Excited-state intramolecular proton-transfer in 2-(2'-hydroxyphenyl)benzimidazole and 2-(2'-hydroxyphenyl)-benzoxazole-effect of rotamerism and hydrogen-bonding. J. Phys. Chem. 1994, 98, 9126-9132. [CrossRef]

37. Raymo, F.M.; Bartberger, M.D.; Houk, K.N.; Stoddart, J.F. The magnitude of [C-H ‥O] hydrogen bonding in molecular and supramolecular assemblies. J. Am. Chem. Soc. 2001, 123, 9264-9267. [CrossRef] [PubMed]

38. Tung, C.H.; Wu, L.Z.; Zhang, L.P.; Chen, B. Supramolecular systems as microreactors: Control of product selectivity in organic phototransformation. Acc. Chem. Res. 2003, 36, 39-47. [CrossRef] [PubMed]

39. Glasbeek, M.; Zhang, H. Femtosecond studies of solvation and intramolecular configurational dynamics of fluorophores in liquid solution. Chem. Rev. 2004, 104, 1929-1954. [CrossRef] [PubMed]

40. Olsen, S.; Smith, S.C. Bond selection in the photoisomerization reaction of anionic green fluorescent protein and kindling fluorescent protein chromophore models. J. Am. Chem. Soc. 2008, 130, 8677-8689. [CrossRef] [PubMed]

41. Cramer, C.J.; Truhlar, D.G. A universal approach to solvation modeling. Acc. Chem. Res. 2008, 41, 760-768. [CrossRef] [PubMed]

42. Zhang, X.; Chi, L.; Ji, S.; Wu, Y.; Song, P.; Han, K.; Guo, H.; James, T.D.; Zhao, J. Rational design of d-PeT phenylethynylated-carbazole monoboronic acid fluorescent sensors for the selective detection of alpha-hydroxyl carboxylic acids and monosaccharides. J. Am. Chem. Soc. 2009, 131, 17452-17463. [CrossRef] [PubMed]

43. Zhao, G.-J.; Han, K.-L. Hydrogen bonding in the electronic excited state. Acc. Chem. Res. 2012, 45, 404-413. [CrossRef] [PubMed]

44. Lan, X.; Yang, D.; Sui, X.; Wang, D. Time-dependent density functional theory (TD-DFT) study on the excited-state intramolecular proton transfer (ESIPT) in 2-hydroxybenzoyl compounds: Significance of the intramolecular hydrogen bonding. Spectrochim. Acta A 2013, 102, 281-285. [CrossRef] [PubMed]

45. Becke, A.D.; Johnson, E.R. Exchange-hole dipole moment and the dispersion interaction revisited. J. Chem. Phys. 2007, 127. [CrossRef] [PubMed]

46. Tsai, H.-H.G.; Sun, H.-L.S.; Tan, C.-J. TD-DFT study of the excited-state potential energy surfaces of 2-(2'-hydroxyphenyl)benzimidazole and its amino derivatives. J. Phys. Chem. A 2010, 114, 4065-4079. [CrossRef] [PubMed]

47. Jayabharathi, J.; Kalaiarasi, V.; Thanikachalam, V.; Jayamoorthy, K. Dynamics of solvent controlled ESIPT of pi-expanded imidazole derivatives-pH Effect. J. Fluoresc. 2014, 24, 625-637. [CrossRef] [PubMed]

48. Mahanta, S.; Paul, B.K.; Singh, R.B.; Guchhait, N. Inequivalence of substitution pairs in hydroxynaphthaldehyde: A theoretical measurement by intramolecular hydrogen bond strength, aromaticity, and excited-state intramolecular proton transfer reaction. J. Comput. Chem. 2011, 32, 1-14. [CrossRef] [PubMed]

49. Roohi, H.; Hejazi, F.; Mohtamedifar, N.; Jahantab, M. Excited state intramolecular proton transfer (ESIPT) in 2-(2'-hydroxyphenyl)benzoxazole and its naphthalene-fused analogs: A TD-DFT quantum chemical study. Spectrochim. Acta A 2014, 118, 228-238. [CrossRef] [PubMed]

50. Alarcos, N.; Gutierrez, M.; Liras, M.; Sanchez, F.; Moreno, M.; Douhal, A. Direct observation of breaking of the intramolecular H-bond, and slowing down of the proton motion and tuning its mechanism in an HBO derivative. Phys. Chem. Chem. Phys. 2015, 17, 14569-14581. [CrossRef] [PubMed]

51. Hsieh, C.-C.; Cheng, Y.-M.; Hsu, C.-J.; Chen, K.-Y.; Chou, P.-T. Spectroscopy and femtosecond dynamics of excited-state proton transfer induced charge transfer reaction. J. Phys. Chem. A 2008, 112, 8323-8332. [CrossRef] [PubMed]

52. Barboza, C.A.; Germino, J.C.; Santana, A.M.; Quites, F.J.; Muniz Vazquez, P.A.; Zambon Atvars, T.D. Structural correlations between luminescent properties and excited state internal proton transfer in some Zinc(II) N,N'-Bis(salicylidenes). J. Phys. Chem. C 2015, 119, 6152-6163. [CrossRef] 
53. Stenson, P. Crystal structure of 2-(ortho hydroxyphenyl) benzothiazole. Acta Chem. Scand. 1970, $24,3729$. [CrossRef]

54. Catalan, J.; del Valle, J.C.; Palomar, J.; Diaz, C.; de Paz, J.L.G. The six-membered intramolecular hydrogen bond position as a switch for inducing an excited state intramolecular proton transfer (ESIPT) in esters of o-hydroxynaphthoic acids. J. Phys. Chem. A 1999, 103, 10921-10934. [CrossRef]

55. Zhao, G.-J.; Liu, J.-Y.; Zhou, L.-C.; Han, K.-L. Site-selective photoinduced electron transfer from alcoholic solvents to the chromophore facilitated by hydrogen bonding: A new fluorescence quenching mechanism. J. Phys. Chem. B 2007, 111, 8940-8945. [CrossRef] [PubMed]

56. Zhao, G.-J.; Han, K.-L. Early time hydrogen-bonding dynamics of photoexcited coumarin 102 in hydrogen-donating solvents: Theoretical study. J. Phys. Chem. A 2007, 111, 2469-2474. [CrossRef] [PubMed]

57. Yang, D.; Zheng, R.; Wang, Y.; Lv, J. The ESIPT mechanism of dibenzimidazolo diimine sensor: A detailed TDDFT study. J. Phys. Org. Chem. 2016, 29, 161-165. [CrossRef]

58. Beg, H.; Das, D.; Ash, S.; Misra, A. Computation of polarizability, hyper-polarizability and hardness as descriptor for enol-keto tautomerizations of 2-hydroxy pyridines. Comput. Theor. Chem. 2013, 1017, 200-207. [CrossRef]

59. Roohi, H.; Mohtamedifar, N.; Hejazi, F. Intramolecular photoinduced proton transfer in 2-(2'-hydroxyphenyl) benzazole family: A TD-DFT quantum chemical study. Chem. Phys. 2014, 444, 66-76. [CrossRef]

60. Li, C.; Yang, Y.; Ma, C.; Liu, Y. Effect of amino group on the excited-state intramolecular proton transfer (ESIPT) mechanisms of 2-(2'-hydroxyphenyl)benzoxazole and its amino derivatives. RSC Adv. 2016, 6, 5134-5140. [CrossRef]

61. Crampton, M.R.; Robotham, I.A. Acidities of some substituted ammonium ions in dimethyl Sulfoxide[dagger]. J. Chem. Res. 1997, 22-23. [CrossRef]

62. Zoltewicz, J.A.; Deady, L.W. Quaternization of heteroaromatic compounds: Quantitative aspects. Adv. Heterocyclic Chem. 1978, 22, 71-121. [CrossRef]

63. Jayabharathi, J.; Thanikachalam, V.; Jayamoorthy, K.; Srinivasan, N. Synthesis, spectral studies and solvatochromism of some novel benzimidazole derivatives-ESIPT process. Spectrochim. Acta A 2013, 105, 223-228. [CrossRef] [PubMed]

64. Wang, R.; Liu, D.; Xu, K.; Li, J. Substituent and solvent effects on excited state intramolecular proton transfer in novel 2-(2'-hydroxyphenyl)benzothiazole derivatives. J. Photochem. Photobiol. A 2009, 205, 61-69. [CrossRef]

65. Latha, V.; Annaraj, B.; Neelakantan, M.A. ESIPT inspired dual fluorescent probe (Z)-3-((4-(4-aminobenzyl) phenyl) amino)-1,3-diphenylprop-2-en-1-one: Experimental and DFT based approach to photophysical properties. Spectrochim. Acta A 2014, 133, 44-53. [CrossRef] [PubMed]

66. Sobolewski, A.L.; Domcke, W. Theoretical investigation of potential-energy surfaces relevant for excited-state hydrogen-transfer in o-hydroxybenzaldehyde. Chem. Phys. 1994, 184, 115-124. [CrossRef]

67. Catalan, J.; Palomar, J.; DePaz, J.L.G. Intramolecular proton or hydrogen-atom transfer in the ground and excited states of 2-hydroxybenzoyl compounds. J. Phis. Chem. A 1997, 101, 7914-7921. [CrossRef]

68. Maheshwari, S.; Chowdhury, A.; Sathyamurthy, N.; Mishra, H.; Tripathi, H.B.; Panda, M.; Chandrasekhar, J. Ground and excited state intramolecular proton transfer in salicylic acid: An ab initio electronic structure investigation. J. Phys. Chem. A 1999, 103, 6257-6262. [CrossRef]

69. De Prasad, S.; Ash, S.; Dalai, S.; Misra, A. A DFT-based comparative study on the excited states intramolecular proton transfer in 1-hydroxy-2-naphthaldehyde and 2-hydroxy-3-naphthaldehyde. J. Mol. Struct. Theochem. 2007, 807, 33-41. [CrossRef]

70. Beg, H.; De Prasad, S.; Ash, S.; Misra, A. Use of polarizability and chemical hardness to locate the transition state and the potential energy curve for double proton transfer reaction: A DFT based study. Comput. Theor. Chem. 2012, 984, 13-18. [CrossRef]

71. Sousa, S.F.; Fernandes, P.A.; Ramos, M.J. General performance of density functionals. J. Phys. Chem. A 2007, 111, 10439-10452. [CrossRef] [PubMed]

72. Zhou, M.; Zhao, J.; Cui, Y.; Wang, Q.; Dai, Y.; Song, P.; Xia, L. Theoretical study on the excited-state intramolecular proton-transfer reaction of 10-hydroxybenzo[h]quinoline in methanol and cyclohexane. J. Lumin. 2015, 161, 1-6. [CrossRef] 
73. Deshmukh, M.S.; Sekar, N. Photophysical properties of ESIPT inspired fluorescent 2-(2-hydroxyphenyl)-6methylimidazo[4,5-f]isoindole-5,7(1H,6H)-dione and its derivative: Experimental and DFT based approach. Spectrochim. Acta A 2015, 135, 457-465. [CrossRef] [PubMed]

74. Paul, B.K.; Guchhait, N. TD-DFT investigation of the potential energy surface for Excited-State Intramolecular Proton Transfer (ESIPT) reaction of 10-hydroxybenzo[h]quinoline: Topological (AIM) and population (NBO) analysis of the intramolecular hydrogen bonding interaction. J. Lumin. 2011, 131, 1918-1926. [CrossRef]

75. Chai, S.; Cong, S.L. Excited state intramolecular proton transfer and substituent effect of 10-hydroxybenzo [h] quinoline: A time-dependent density functional theory study. Comput. Theor. Chem. 2014, 1034, 80-84. [CrossRef]

76. Deshmukh, M.S.; Sekar, N. Chemiluminescence properties of luminol related o-hydroxybenzimidazole analogues: Experimental and DFT based approach to photophysical properties. Dyes Pigment. 2015, 113, 189-199. [CrossRef]

77. Kataria, S.; Rhyman, L.; Ramasami, P.; Sekar, N. Comprehensive DFT and TD-DFT studies on the photophysical properties of 5,6-dichloro-1,3-Bis(2-Pyridylimino)-4,7-Dihydroxyisoindole: A new class of ESIPT fluorophore. J. Fluoresc. 2016, 26, 1805-1812. [CrossRef] [PubMed]

78. Zhao, G.J.; Han, K.L. Novel infrared spectra for intermolecular dihydrogen bonding of the phenolborane-trimethylamine complex in electronically excited state. J. Chem. Phys. 2007, 127, 024306. [CrossRef] [PubMed]

79. Zhao, G.J.; Han, K.L. Effects of hydrogen bonding on tuning photochemistry: Concerted hydrogen-bond strengthening and weakening. Chem. Phys. Chem. 2008, 9, 1842-1846. [CrossRef] [PubMed]

80. Zhao, G.J.; Han, K.L. Time-dependent density functional theory study on hydrogen-bonded intramolecular charge-transfer excited state of 4-dimethylamino-benzonitrile in methanol. J. Comput. Chem. 2008, 29, 2010-2017. [CrossRef] [PubMed]

81. Zhao, G.J.; Northrop, B.H.; Han, K.L.; Stang, P.J. The effect of intermolecular hydrogen bonding on the fluorescence of a bimetallic platinum complex. J. Phys. Chem. A 2010, 114, 9007-9013. [CrossRef] [PubMed]

82. Yu, F.; Li, P.; Li, G.; Zhao, G.; Chu, T.; Han, K. A Near-IR reversible fluorescent probe modulated by selenium for monitoring peroxynitrite and imaging in living cells. J. Am. Chem. Soc. 2011, 133, 11030-11033. [CrossRef] [PubMed]

83. Zhao, G.J.; Chen, R.K.; Sun, M.T.; Liu, J.Y.; Li, G.Y.; Gao, Y.L.; Han, K.L.; Yang, X.C.; Sun, L. Photoinduced intramolecular charge transfer and S-2 fluorescence in thiophene-pi-conjugated donor-acceptor systems: Experimental and TDDFT studies. Chem. Eur. J. 2008, 14, 6935-6947. [CrossRef] [PubMed]

84. Dickson, R.M.; Becke, A.D. Basis-set-free local density-functional calculations of geometries of polyatomicmolecules. J. Chem. Phys. 1993, 99, 3898-3905. [CrossRef]

85. Lee, C.T.; Yang, W.T.; Parr, R.G. Development of the colle-salvetti correlation-energy formula into a functional of the electron density. Phys. Rev. B 1988, 37, 785-789. [CrossRef]

86. Becke, A.D. Density-functional thermochemistry. III. The role of exact exchange. J. Phys. Chem. 1993, 98, 5648-5652. [CrossRef]

87. Becke, A.D. Density-functional exchange-energy approximation with correct asymptotic-behavior. Phys. Rev. A 1988, 38, 3098-3100. [CrossRef]

88. Feller, D.J. The role of databases in support of computational chemistry calculations. J. Comp. Chem 1996, 17, 1571-1586. [CrossRef]

89. Neese, F. The ORCA program system. WIREs Comput. Mol. Sci. 2012, 2, 73-78. [CrossRef]

Sample Availability: not available. 